Article

\title{
OcUGT1-Catalyzed Glucosylation of Sulfuretin Yields Ten Glucosides
}

\author{
Shuai Yuan ${ }^{1}$, Yan-Li Xu ${ }^{1}$, Yan Yang ${ }^{1}$ and Jian-Qiang Kong $1,2, *$ (I) \\ 1 State Key Laboratory of Bioactive Substance and Function of Natural Medicines \& Ministry of Health Key \\ Laboratory of Biosynthesis of Natural Products, Institute of Materia Medica, Chinese Academy of Medical \\ Sciences \& Peking Union Medical College, Beijing 100050, China; yuanshuai@imm.ac.cn (S.Y.); \\ yanlixu@imm.ac.cn (Y.-L.X.); yangyan@imm.ac.cn (Y.Y.) \\ 2 Hebei LANSEN Biotech. Co. Ltd., Jinzhou 052263, China \\ * Correspondence: jianqiangk@imm.ac.cn; Tel.: +86-106-303-3559
}

Received: 2 September 2018; Accepted: 20 September 2018; Published: 25 September 2018

check for updates

\begin{abstract}
Sulfuretin glucosides are important sources of innovative drugs. However, few glucosides of sulfuretin have been observed in nature. Therefore, it is urgent to diversify sulfuretin glycosides. Herein, glycosyltransferase (GT)-catalyzed glycodiversification of sulfuretin was achieved. Specifically, a flavonoid GT designated as OcUGT1 was used as a biocatalyst for the glucosylation of sulfuretin with UDP-Glc. The OcUGT1-assisted glucosylation of sulfuretin yielded ten glycosylated products, including three monoglucosides, five diglucosides and two triglucosides. The three monoglucosides were thus identified to be sulfuretin $3^{\prime}-4^{\prime}$ - and 6-glucoside according to HR-ESI-TOFMS data and their coelution with respective standards. A major diglucoside was assigned as sulfuretin $4^{\prime}$,6-diglucoside by HR-ESI-TOFMS in conjunction with NMR analysis. The exact structure of the other four diglucosides was not well characterized due to their trace amount. However, they were reasonably inferred as sulfuretin $3^{\prime}, 6$-diglucoside, sulfuretin $3^{\prime}, 4^{\prime}$-diglucoside and two disaccharide glucosides. In addition, the structural identification of the remaining two triglucosides was not performed because of their small amount. However, one of the triglucosides was deduced to be sulfuretin $3^{\prime}, 4^{\prime}$,6-triglucoside based on the catalytic behavior of OcUGT1. Of the ten sulfuretin glucosides, at least six were new compounds. This is the first time to obtain monoglucosides, diglucosides and triglucosides of sulfuretin simultaneously by a single glycosyltransferase.
\end{abstract}

Keywords: glycosyltransferase; glycodiverfication; sulfuretin; OcUGT1

\section{Introduction}

Glycodiversification is a collective strategy of natural product glycosylation, in which varied activated sugars are attached to natural-product acceptors by enzymatic or chemical means, thereby providing diverse carbohydrate structures and functions [1,2]. The resultant glycosylated bioactive compounds have been shown to exert various biological and pharmacological activities with improved physicochemical characters, such as solubility and stability [3,4]. Many glycosides are thus developed to clinical drugs, e.g., rutin [5-7], puerarin [8] and scutellarin [9]. Hence, glycodiversification of natural products is deemed an effective strategy to broaden the scope of new compounds [2].

Owing to the structural complexity of many glycosylated compounds, glycodiversification of natural products by chemical synthesis may be a formidable task [2]. Conversely, enzymatic glycodiversification is becoming a main strategy for diversifying glycosylated natural products due to the great strides made in the generation of glycosyltransferase with catalytic promiscuity [10-13].

Sulfuretin (1, also designated as sulphuretin, Figure 1 and Figure S1), a naturally occurring aurone [14-16], is found to display a remarkable spectrum of biological activities such as therapeutic 
activity against acquired lymphedema [14], anti-Parkinson's disease activity [15], antioxidant action [16], therapeutic benefits in bone disease and regeneration [17,18] and neuroprotective effect [19], suggesting sulfuretin is a promising molecule for drug development. Accordingly, the interest for the discovery or synthesis of sulfuretin derivatives is increasing. Many sulfuretin derivatives featuring varied functional groups were thus observed to display a wide range of biological activities [20-23]. Of these derivatives, glycosides of sulfuretin, e.g., sulfuretin 6-glucoside (sulfurein) [24-26], sulfuretin 3'-glucoside [25] and palasitrin (sulfuretin 3',6-diglucoside) [27], have been determined to exhibit diverse activities such as antioxidant activity $[26,28]$ and influenza A neuraminidase inhibitory activity [25], suggesting sulfuretin glycosides are a potent source of drug discovery. Thus far, however, few sulfuretin glycosides have been obtained through direct extraction or enzymatic synthesis [29,30], which limited their druggability study. Therefore, it is urgent to diversify sulfuretin glycosides for drug screening.

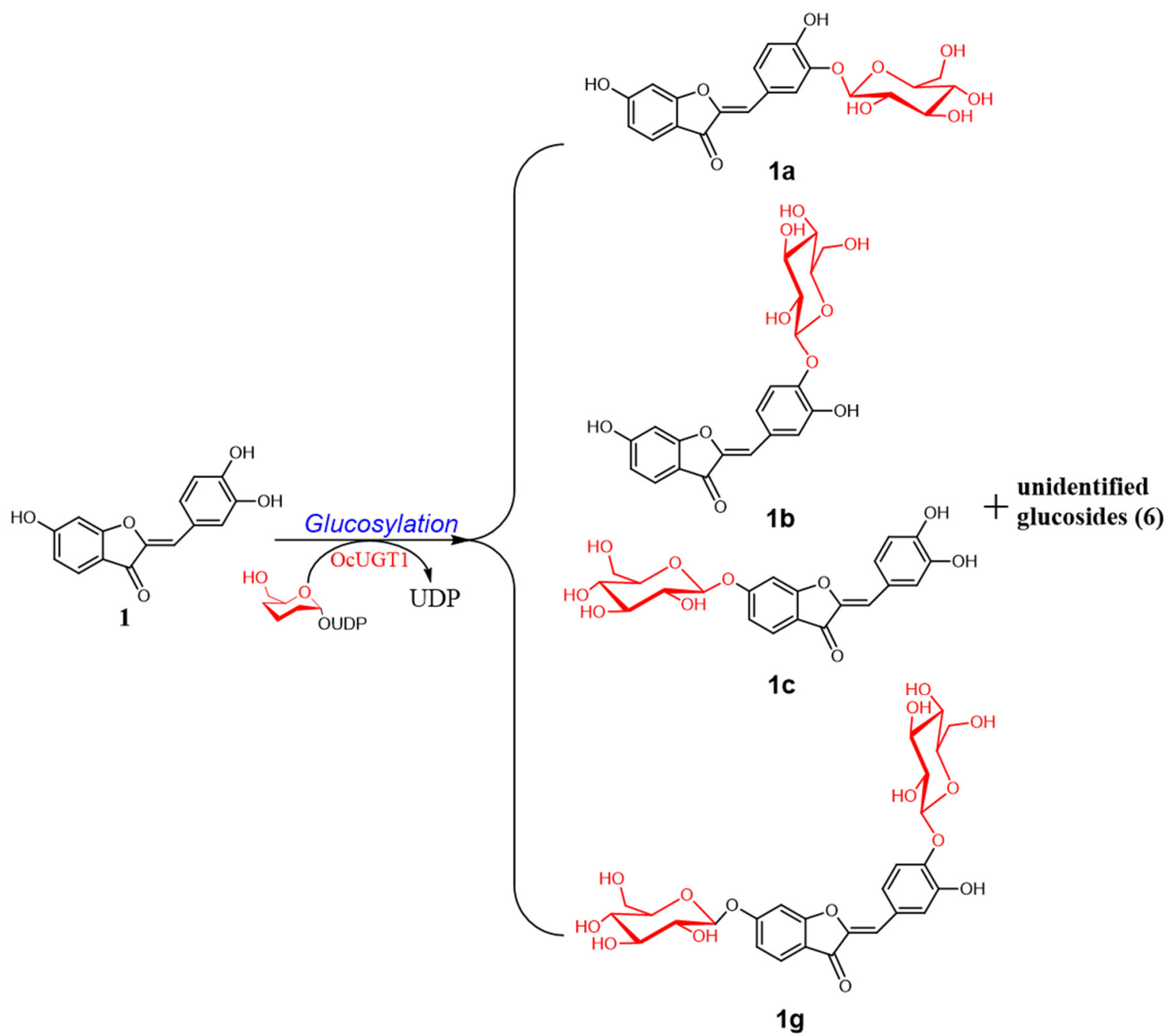

Figure 1. OcUGT1-catalyzed glucosylation of sulfuretin (1) resulted in the generation of ten glucosides (1a, 1b, 1c, $1 \mathrm{~g}$ and six unidentified compounds).

OcUGT1 (Ornithogalum caudatum UDP-glycosyltransferase), isolated from O. caudatum previously [13], is a flavonoid glycosyltransferase (GT) with catalyzing promiscuity. OcUGT1 can glucosylate diverse sugar acceptors including flavonoids. Moreover, OcUGT1 has been observed to function on multiple sites of flavonoids, yielding a number of flavonoid glycosides [13]. Both indicate OcUGT1 is an ideal tool for glycodiversification of small molecules. OcUGT1 was used as a biocatalyst 
for the glucosylation of sulfuretin with UDP-D-glucose (UDP-Glc). OcUGT1-assisted glucosylation of sulfuretin resulted in the formation of ten glucosides including three monoglucosides, five diglucosides and two triglucosides. Of these ten newly formed glycosides, at least six glucosides were new compounds (Figure 1). Thus, the use of single glycosyltransferases capable of forming multiple glycosides is an effective way to achieve glycosidic diversification, and can significantly increase the probability of drug discovery.

\section{Results and Discussion}

\subsection{Protein Expression and Purification}

After induction by IPTG, total proteins of Escherichia coli strain BL21(DE3) [pET28a-OcUGT1 + pKJE7] were subject to sodium dodecyl sulfate polyacrylamide gel electrophoresis (SDS-PAGE) analysis [13]. As shown in Figure 2A, an intense band with $53 \mathrm{kDa}$ was detected in the sample. No corresponding band was present in the control strain, suggesting a soluble OcUGT1 was expressed in E. coli (Figure 2). The expressed OcUGT1 was thus purified to near homogeneity and its concentration was determined for glucosylation reaction.

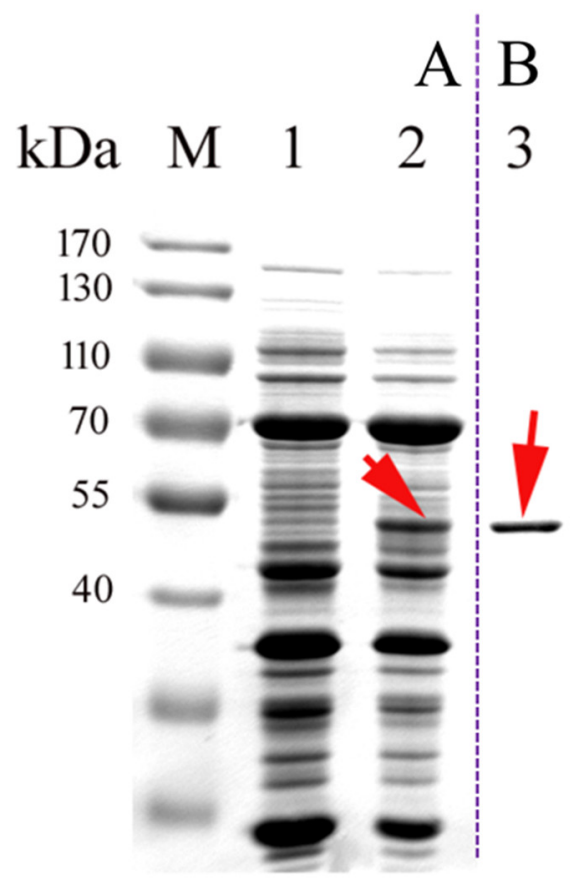

Figure 2. Heterologous expression (A) and affinity purification (B) of OcUGT1. 1, total protein of the control strain BL21(DE3) [pET-28a (+)+pKJE7]; 2, total protein of BL21(DE3) [pET28a-OcUGT1 + pKJE7]; and 3, the purified OcUGT1 protein. Values at the left margin indicate the position and molecular mass of protein standards. Red arrows show the recombinant OcUGT1.

\subsection{OcUGT1-Catalyzed Glycosylation towards Sulfuretin}

After incubated at $50{ }^{\circ} \mathrm{C}$ for $2 \mathrm{~h}$, the reaction mixture containing purified OcUGT1, sulfuretin and UDP-Glc was analyzed by reverse phase high performance liquid chromatography (RP-HPLC). As shown in Figure 3, ten new peaks 1a-j were present in the reaction mixture (Figure 3), while there were no new peaks in the control reaction harboring no purified OcUGT1 (Figure 3) suggesting the ten peaks might be glucosylated metabolites of sulfuretin. 


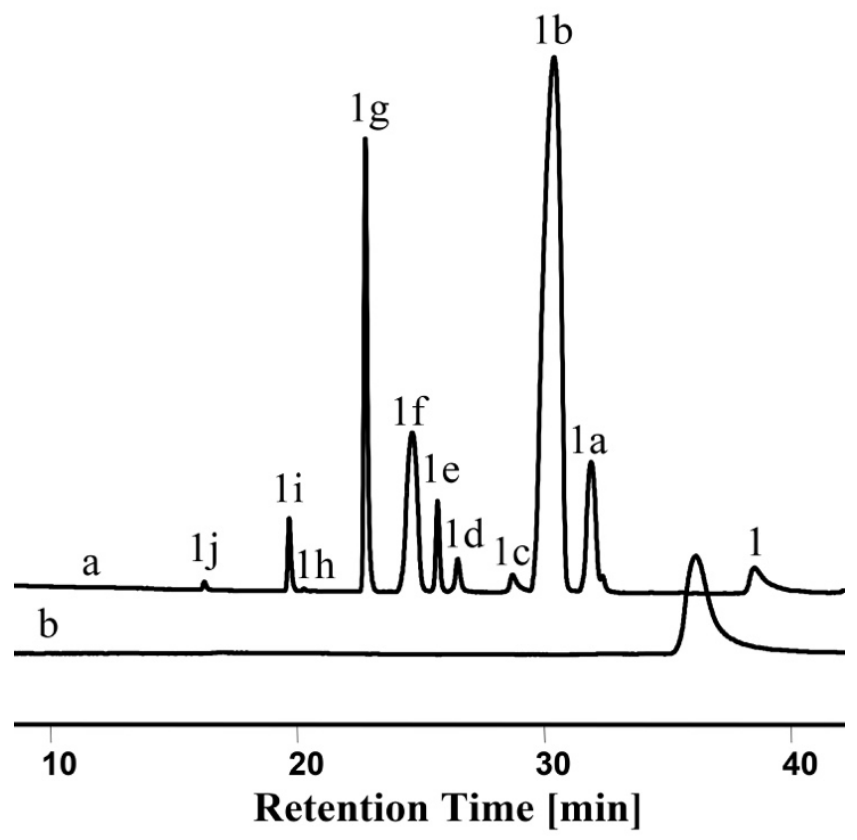

Figure 3. HPLC chromatogram of the glucosylated metabolites of sulfuretin with (a) or without (b) purified OcUGT1.

\subsection{Structural Identification of Sulfuretin Monoglucosides}

The ten metabolites were then subjected to high-resolution electrospray ionization mass spectrometry (HR-ESI-MS) analyses. The positive ion HR-ESI-MS spectrum of 1a displayed a molecular ion peak at $m / z 455.0928[\mathrm{M}+\mathrm{Na}]^{+}$corresponding to $\mathrm{C}_{21} \mathrm{H}_{20} \mathrm{O}_{10} \mathrm{Na}$ (Figure S2). The major metabolite $1 \mathrm{~b}$ exhibited a pseudomolecular ion peak $[\mathrm{M}+\mathrm{Na}]^{+}$at $m / z 455.0927$, and the molecular formula $\mathrm{C}_{21} \mathrm{H}_{20} \mathrm{O}_{10} \mathrm{Na}$ was established by HR-ESI-MS (Figure S2). The molecular formula of a minor product 1c was determined to be $\mathrm{C}_{21} \mathrm{H}_{20} \mathrm{O}_{10} \mathrm{Na}$, by HR-ESI-MS at $m / z 455.0943[\mathrm{M}+\mathrm{Na}]^{+}$(Figure S2). The evidence suggests that all three metabolites were monoglucosylated sulfuretins. Coelutions of these metabolites with their standards assigned $\mathbf{1 a}, \mathbf{1} \mathbf{b}$ and $\mathbf{1} \mathbf{c}$ to be sulfuretin $3^{\prime}-4^{\prime}$ - and 6 -glucoside, respectively [29].

\subsection{Structural Identification of Sulfuretin Diglucosides}

Compounds $1 \mathrm{~d}, \mathbf{1 e}, \mathbf{1 f}, \mathbf{1}$ and $\mathbf{1 h}$ have the same molecular formula $\mathrm{C}_{27} \mathrm{H}_{30} \mathrm{O}_{15} \mathrm{Na}$ with $[\mathrm{M}+\mathrm{Na}]^{+}$ ion peaks at $m / z 617.1479,617.1484,617.1492,617.1481$ and 617.1500 , respectively, suggesting their diglucosylation of sulfuretin (Figure S3). Compound $1 \mathrm{~g}$ is the major product of these sulfuretin diglucosides. To further determine the structure of $1 \mathrm{~g}$, it was collected using RP-HPLC and subjected to nuclear magnetic resonance (NMR) analyses. The ${ }^{1} \mathrm{H}-\mathrm{NMR}$ spectrum (Figure $\mathrm{S} 4$ and Table 1) showed signals for the following protons: an olefinic proton at $\delta 6.77(1 \mathrm{H}, \mathrm{s}, \mathrm{H}-10)$; and two sets of ABX type aromatic protons at $\delta 7.71(1 \mathrm{H}, \mathrm{d}, J=8.5 \mathrm{~Hz}, \mathrm{H}-4), 6.92(1 \mathrm{H}, \mathrm{dd}, J=2.0,8.5 \mathrm{~Hz}, \mathrm{H}-5), 7.21$ $(1 \mathrm{H}, \mathrm{d}, J=2.0 \mathrm{~Hz}, \mathrm{H}-7)$, and $7.49\left(1 \mathrm{H}, \mathrm{d}, J=2.1 \mathrm{~Hz}, \mathrm{H}-2^{\prime}\right), 7.21\left(1 \mathrm{H}, \mathrm{d}, J=8.6 \mathrm{~Hz}, \mathrm{H}-5^{\prime}\right), 7.41(1 \mathrm{H}, \mathrm{dd}$, $\left.J=2.1,8.6 \mathrm{~Hz}, \mathrm{H}-6^{\prime}\right)$. The ${ }^{13} \mathrm{C}-\mathrm{NMR}$ and spectroscopic data (Figure S4 and Table 1) indicated 27 carbon resonances, including two glucose moiety carbons, one carbonyl carbon, five aromatic oxygenated carbons, and nine aromatic carbons. The above data revealed that compound $1 \mathrm{~g}$ has a typical sulfuretin skeleton. In the HMBC (Figure 4 and Figure S5) spectrum of compound 1g, long-range correlations between $\mathrm{H}-1^{\prime \prime}$ and $\mathrm{C}-6(\delta 164.9), \mathrm{H}-1^{\prime \prime \prime}$ and C-4 ${ }^{\prime}(\delta 146.7)$, demonstrated that the glucosyl group was located at $\mathrm{C}-6$ and $\mathrm{C}-4^{\prime}$, respectively. The $\beta$-configuration of sugars were concluded from the anomeric proton signals at $\delta 5.18\left(1 \mathrm{H}, \mathrm{d}, 7.3 \mathrm{~Hz}, \mathrm{H}-1^{\prime \prime}\right)$, and $4.84\left(1 \mathrm{H}, \mathrm{d}, 7.3 \mathrm{~Hz}, \mathrm{H}-1^{\prime \prime \prime}\right)$ in the ${ }^{1} \mathrm{H}-\mathrm{NMR}$ spectrum. Based on these observations, the metabolite $1 \mathrm{~g}$ was elucidated as sulfuretin $4^{\prime}, 6$-diglucoside (Figure 4 , Figure S1, S4 and S5 and Table 1). The four other diglucosides were not well characterized due to 
their trace amount. According to the catalytic behavior of OcUGT1 towards luteolin [13], the four diglucosides should include sulfuretin $3^{\prime}, 6$-diglucoside and sulfuretin $3^{\prime}, 4^{\prime}$-diglucoside. Previous study indicated that OcUGT1 was able to attack the hydroxyl group of sugar moiety in monoglucosides, thereby forming disaccharide glycosides [30]. It is therefore reasonable to infer the remaining two diglucosides were disaccharide glucosides of sulfuretin. Thus, OcUGT1-assisted glucosylation of sulfuretin resulted in five diglucosides, namely sulfuretin 4',6-diglucoside (1g) (Figure S1), sulfuretin $3^{\prime}, 6$-diglucoside, sulfuretin $3^{\prime}, 4^{\prime}$-diglucoside and two disaccharide glucosides (Figure 1). Of the five diglucosides, the two diglucoside sulfuretin $4^{\prime}, 6$-diglucoside (19) and sulfuretin $3^{\prime}, 4^{\prime}$-diglucoside, as well as two disaccharide glucosides of sulfuretin, were new compounds.

Table 1. ${ }^{1} \mathrm{H}$ - and ${ }^{13} \mathrm{C}-\mathrm{NMR}$ data of the compound $\mathbf{1 g}$.

\begin{tabular}{|c|c|c|}
\hline Position & ${ }^{13} \mathrm{C}$ & ${ }^{1} \mathbf{H}$ \\
\hline 2 & $146.2, \mathrm{C}$ & \\
\hline 3 & $181.7, \mathrm{C}$ & \\
\hline 4 & $125.4, \mathrm{CH}$ & 7.71, d (8.5) \\
\hline 5 & $113.7, \mathrm{CH}$ & $6.92, \mathrm{dd}(8.5,2.0)$ \\
\hline 6 & $164.9, \mathrm{C}$ & \\
\hline 7 & $99.4, \mathrm{CH}$ & $7.21, \mathrm{~d}(2.0)$ \\
\hline 8 & $167.4, \mathrm{C}$ & \\
\hline 9 & $115.1, \mathrm{C}$ & \\
\hline 10 & $111.9, \mathrm{CH}$ & $6.77, \mathrm{~s}$ \\
\hline $1^{\prime}$ & $126.3, \mathrm{C}$ & \\
\hline $2^{\prime}$ & $118.2, \mathrm{CH}$ & $7.49, \mathrm{~d}(2.1)$ \\
\hline $3^{\prime}$ & $147.2, \mathrm{C}$ & \\
\hline $4^{\prime}$ & $146.7, \mathrm{C}$ & \\
\hline $5^{\prime}$ & $116.0, \mathrm{CH}$ & 7.21, d (8.6) \\
\hline \multirow[t]{2}{*}{$6^{\prime}$} & $124.0, \mathrm{CH}$ & 7.41, dd $(8.6,2.1)$ \\
\hline & Glc & Glc \\
\hline $1^{\prime \prime}$ & $101.4, \mathrm{CH}$ & $5.18, \mathrm{~d}(7.3)$ \\
\hline $2^{\prime \prime}$ & $73.3, \mathrm{CH}$ & \\
\hline $3^{\prime \prime}$ & $76.4, \mathrm{CH}$ & \\
\hline $4^{\prime \prime}$ & $69.9, \mathrm{CH}$ & 3.0-3.8, m (overlapped) \\
\hline $5^{\prime \prime}$ & $77.3, \mathrm{CH}$ & \\
\hline $6^{\prime \prime}$ & $\begin{array}{c}60.8, \mathrm{CH}_{2} \\
\text { Glc }\end{array}$ & \\
\hline $1^{\prime \prime \prime}$ & $99.7, \mathrm{CH}$ & $4.84, \mathrm{~d}(7.3)$ \\
\hline $2^{\prime \prime \prime}$ & $73.1, \mathrm{CH}$ & \\
\hline $3^{\prime \prime \prime}$ & $75.8, \mathrm{CH}$ & \\
\hline $4^{\prime \prime \prime}$ & $69.6, \mathrm{CH}$ & 3.0-3.8, m (overlapped) \\
\hline $5^{\prime \prime \prime}$ & $77.1, \mathrm{CH}$ & \\
\hline $6^{\prime \prime \prime}$ & $60.7, \mathrm{CH}_{2}$ & \\
\hline
\end{tabular}

\subsection{Structural Identification of Sulfuretin Triglucosides}

The HR-ESI-MS of $1 \mathrm{i}$ and $1 \mathrm{j}$ displayed molecular ion $[\mathrm{M}+\mathrm{Na}]^{+}$peaks at $m / z 779.2011$ and 779.2031, respectively, both corresponding to the molecular formula of $\mathrm{C}_{33} \mathrm{H}_{40} \mathrm{O}_{20} \mathrm{Na}$, which indicated that both compounds were triglucosides of sulfuretin (Figure S6). The structures of the two triglucosides were not well characterized due to their trace amount. According to the catalytic behavior of OcUGT1 [13], one of the triglucosides was sulfuretin $3^{\prime}, 4^{\prime}, 6$-triglucoside. The other triglucoside could not been deduced from the HR-ESI-MS data. To the best of our knowledge, the two triglucosides were also new compounds. 


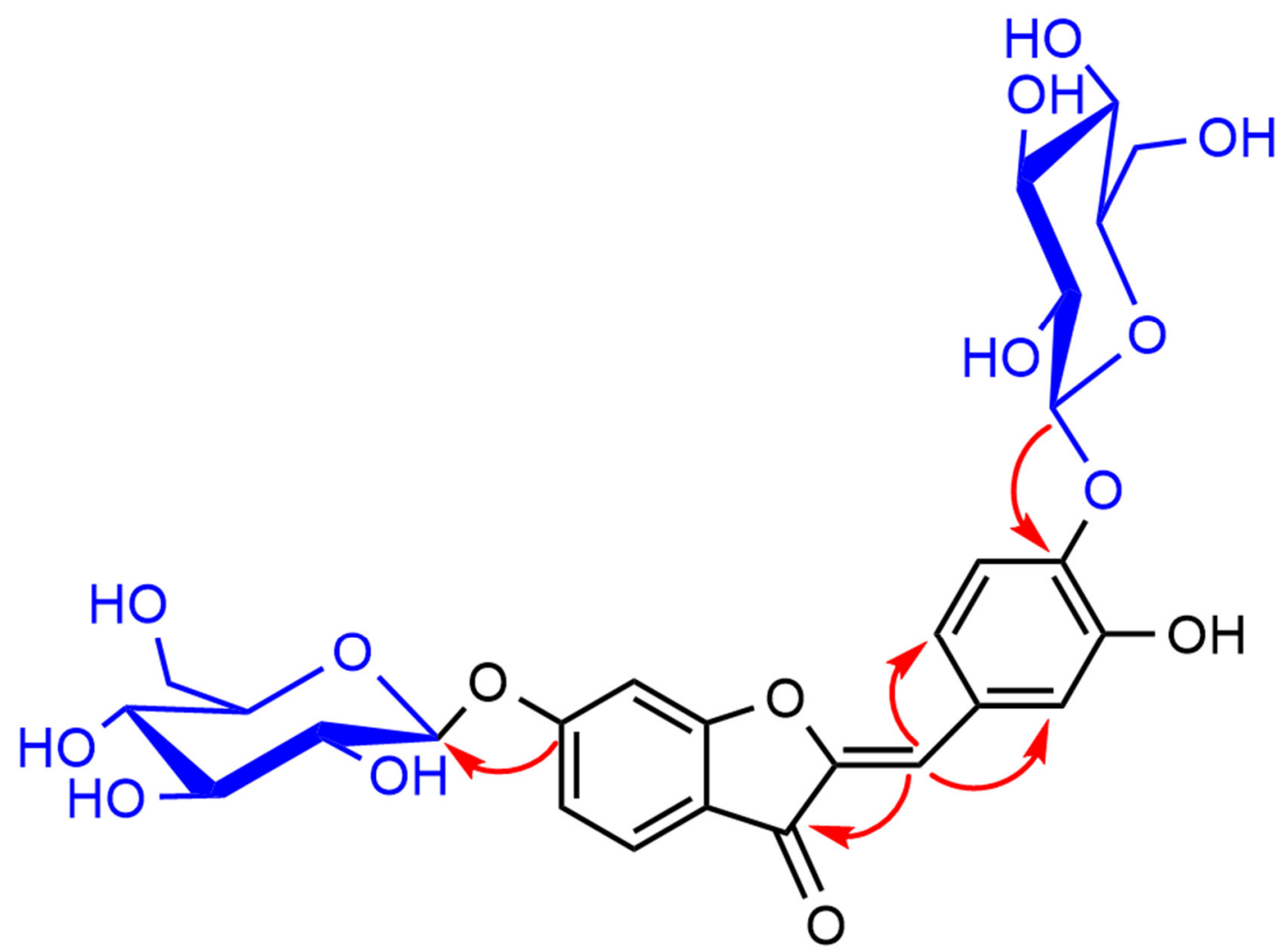

Figure 4. Selected HMBC (arrows) correlations of $\mathbf{1 g}$.

Overall, OcUGT1-catalyzed glucosylation of sulfuretin led to the generation of ten glucosides including six new compounds. The data revealed that enzyme-mediated glucosylation is an effective way to diversify glucosides. Previously, glycosyltransferases capable of accepting glycosides for further glycosylation have been reported [3]. However, there are few glycosyltransferases that catalyze the formation of monoglycosides, diglucosides and triglycosides of a single substrate simultaneously. In this study, OcUGT1 has been demonstrated to catalyze sulfuretin to form corresponding monoglycosides, disaccharides and triglycosides simultaneously, indicating that OcUGT1 has a very wide substrate specificity. These results, together with previous reports $[13,31,32]$, indicate that OcUGT1 has potential applications as a biocatalyst in glycodiversification of natural products.

\section{Materials and Methods}

\subsection{Chemicals}

Sulfuretin (CAS No.:120-05-8) was purchased from BioBioPha (Kunming, Yunnan, China) (Figure S1). UDP-Glc was obtained from Sigma-Aldrich Co. LLC (St. Louis, MO, USA). The other chemicals were either reagents or analytical grade when available.

\subsection{Protein Expression and Purification}

Heterologous expression and purification of OcUGT1 was performed as described previously [13]. As introduced by Yuan et al., an expression plasmid pET28a-OcUGT1 and a chaperone plasmid pKJE7 (Takara, Dalian, China) were co-transformed into E. coli strain BL21 (DE3) for soluble expression. Total protein extracts from isopropyl- $\beta$-D-thiogalactoside (IPTG)-induced bacterial cells were separated by SDS-PAGE. The expressed recombinant protein with His-Tag were purified by affinity chromatography. The concentration of the purified protein was determined based on the procedure introduced by Yin et al. [33]. The resultant purified OcUGT1 was applied as the biocatalyst for the glycosylation towards sulfuretin (1) (Figure S1). 


\subsection{Glycosylation Assay}

The reaction mixture and reaction conditions of OcUGT1-catalyzed glycosylation assay was the same as that of our previous reports [13]. In brief, a total of $100 \mu \mathrm{L}$ phosphate buffer (10 mM, pH 8.0) harboring $10 \mathrm{mg}$ purified OcUGT1, $1 \mathrm{mM}$ sulfuretin and $1 \mathrm{mM} \mathrm{UDP-Glc}$ were incubated at $50{ }^{\circ} \mathrm{C}$ for $2 \mathrm{~h}$. The glycosylation reaction was monitored by RP-HPLC. The HPLC conditions were the same as previously described by Yuan et al. [13].

\subsection{Structural Identification}

HR-ESI-MS spectra were recorded on A Triple TOFTM 5600 system (AB SCIEX, CA, USA) with a DuoSpray ionization source operating in the positive ESI mode.

NMR spectroscopic data were obtained as previously described [29,34-36]. Chemical shifts $(d)$ and coupling constants $(J)$ were provided in ppm and hertz $(\mathrm{Hz})$, respectively.

Supplementary Materials: The following are available online at http:/ / www.mdpi.com/2073-4344/8/10/416/s1, Figure S1: he general position numeration of sulfuretin (1) and sulfuretin 4',6-diglucoside (1g), Figure S2: The mass spectra of $\mathbf{1 a}(\mathrm{A}), \mathbf{1 b}(\mathrm{B})$ and $\mathbf{1 c}(\mathrm{C})$ acquired by ESI-HRMS, Figure S3: The mass spectra of $\mathbf{1 d}(\mathrm{A}), \mathbf{1 e}(\mathrm{B})$ $1 \mathrm{f}(\mathrm{C}), \mathbf{1 g}(\mathrm{D})$ and $\mathbf{1 h}(\mathrm{E})$ acquired by ESI-HRMS, Figure S4: ${ }^{1} \mathrm{H}-\mathrm{NMR}$ spectrum (600 MHz, DMSO-d6) (A) and ${ }^{13}$ C-NMR spectrum of $\mathbf{1 g}(150 \mathrm{MHz}$, DMSO-d6) (B), Figure S5: HMBC spectrum of 1g, Figure S6: The mass spectra of $\mathbf{1 i}(\mathrm{A})$ and $\mathbf{1 j}(\mathrm{B})$ acquired by ESI-HRMS.

Author Contributions: Conceptualization, J.-Q.K.; Investigation, S.Y. and Y.L.X.; Validation, S.Y., Y.Y. and J.-Q.K.; Writing—Original Draft Preparation, J.-Q.K.; Supervision, Writing—review \& editing, J.-Q.K.

Funding: This work was supported by the CAMS Innovation Fund for Medical Sciences (CIFMS) (2016-I2M-3-012) and Beijing Natural Science Foundation (7172143).

Conflicts of Interest: The authors declare no conflicts of interest.

\section{Abbreviations}

GT

HR-ESI-MS high-resolution electrospray ionization mass spectrometry

IPTG isopropyl- $\beta$-D-thiogalactoside

NMR nuclear magnetic resonance

OcUGT1 Ornithogalum caudatum UDP-glycosyltransferase

RP-HPLC reverse phase high performance liquid chromatography

SDS-PAGE sodium dodecyl sulfate polyacrylamide gel electrophoresis

UDP-Glc UDP-D-glucose

\section{References}

1. Thibodeaux, C.J.; Melancon, C.E., 3rd; Liu, H.W. Natural-product sugar biosynthesis and enzymatic glycodiversification. Angew. Chem. Int. Ed. Engl. 2008, 47, 9814-9859. [CrossRef] [PubMed]

2. Thibodeaux, C.J.; Melancon, C.E.; Liu, H.W. Unusual sugar biosynthesis and natural product glycodiversification. Nature 2007, 446, 1008-1016. [CrossRef] [PubMed]

3. Hofer, B. Recent developments in the enzymatic O-glycosylation of flavonoids. Appl. Microbiol. Biotechnol. 2016, 100, 4269-4281. [CrossRef] [PubMed]

4. Xiao, J.; Muzashvili, T.S.; Georgiev, M.I. Advances in the biotechnological glycosylation of valuable flavonoids. Biotechnol. Adv. 2014, 32, 1145-1156. [CrossRef] [PubMed]

5. Al-Dhabi, N.A.; Arasu, M.V.; Park, C.H.; Park, S.U. An up-to-date review of rutin and its biological and pharmacological activities. EXCLI J. 2015, 14, 59-63. [PubMed]

6. Sharma, S.; Ali, A.; Ali, J.; Sahni, J.K.; Baboota, S. Rutin: Therapeutic potential and recent advances in drug delivery. Expert Opin. Investig. Drugs 2013, 22, 1063-1079. [CrossRef] [PubMed]

7. Chua, L.S. A review on plant-based rutin extraction methods and its pharmacological activities. J. Ethnopharmacol. 2013, 150, 805-817. [CrossRef] [PubMed] 
8. Zhao, J.; Luo, D.; Liang, Z.; Lao, L.; Rong, J. Plant natural product puerarin ameliorates depressive behaviors and chronic pain in mice with spared nerve injury (SNI). Mol. Neurobiol. 2017, 54, 2801-2812. [CrossRef] [PubMed]

9. Yuan, Y.; Fang, M.; Wu, C.Y.; Ling, E.A. Scutellarin as a potential therapeutic agent for microglia-mediated neuroinflammation in cerebral ischemia. Neuromol. Med. 2016, 18, 264-273. [CrossRef] [PubMed]

10. Sun, L.; Chen, D.; Chen, R.; Xie, K.; Liu, J.; Yang, L.; Dai, J. Exploring the aglycon promiscuity of a new glycosyltransferase from Pueraria lobata. Tetrahedron Lett. 2016, 57, 1518-1521. [CrossRef]

11. Chen, D.; Chen, R.; Wang, R.; Li, J.; Xie, K.; Bian, C.; Sun, L.; Zhang, X.; Liu, J.; Yang, L.; et al. Probing the catalytic promiscuity of a regio- and stereospecific c-glycosyltransferase from Mangifera indica. Angew. Chem. Int. Ed. Engl. 2015, 54, 12678-12682. [CrossRef] [PubMed]

12. Xie, K.; Chen, R.; Li, J.; Wang, R.; Chen, D.; Dou, X.; Dai, J. Exploring the catalytic promiscuity of a new glycosyltransferase from Carthamus tinctorius. Org. Lett. 2014, 16, 4874-4877. [CrossRef] [PubMed]

13. Yuan, S.; Yin, S.; Liu, M.; Kong, J.-Q. Isolation and characterization of a multifunctional flavonoid glycosyltransferase from Ornithogalum caudatum with glycosidase activity. Sci. Rep. 2018, 8, 5886. [CrossRef] [PubMed]

14. Roh, K.; Kim, S.; Kang, H.; Ku, J.M.; Park, K.W.; Lee, S. Sulfuretin has therapeutic activity against acquired lymphedema by reducing adipogenesis. Pharmacol. Res. 2017, 121, 230-239. [CrossRef] [PubMed]

15. Pariyar, R.; Lamichhane, R.; Jung, H.J.; Kim, S.Y.; Seo, J. Sulfuretin attenuates MPP (+)-induced neurotoxicity through Akt/GSK3beta and ERK signaling pathways. Int. J. Mol. Sci. 2017, 18, 2753. [CrossRef] [PubMed]

16. Chand, K.; Hiremathad, A.; Singh, M.; Santos, M.A.; Keri, R.S. A review on antioxidant potential of bioactive heterocycle benzofuran: Natural and synthetic derivatives. Pharmacol. Rep. 2017, 69, 281-295. [CrossRef] [PubMed]

17. Auh, Q.S.; Park, K.R.; Yun, H.M.; Lim, H.C.; Kim, G.H.; Lee, D.S.; Kim, Y.C.; Oh, H.; Kim, E.C. Sulfuretin promotes osteoblastic differentiation in primary cultured osteoblasts and in vivo bone healing. Oncotarget 2016, 7, 78320-78330. [CrossRef] [PubMed]

18. Song, N.J.; Kwon, S.M.; Kim, S.; Yoon, H.J.; Seo, C.R.; Jang, B.; Chang, S.H.; Ku, J.M.; Lee, J.S.; Park, K.M.; et al. Sulfuretin induces osteoblast differentiation through activation of TGF-beta signaling. Mol. Cell Biochem. 2015, 410, 55-63. [CrossRef] [PubMed]

19. Kwon, S.-H.; Ma, S.-X.; Lee, S.-Y.; Jang, C.-G. Sulfuretin inhibits 6-hydroxydopamine-induced neuronal cell death via reactive oxygen species-dependent mechanisms in human neuroblastoma SH-SY5Y cells. Neurochem. Int. 2014, 74, 53-64. [CrossRef] [PubMed]

20. Lee, Y.H.; Shin, M.C.; Yun, Y.D.; Shin, S.Y.; Kim, J.M.; Seo, J.M.; Kim, N.-J.; Ryu, J.H.; Lee, Y.S. Synthesis of aminoalkyl-substituted aurone derivatives as acetylcholinesterase inhibitors. Bioorgan. Med. Chem. 2015, 23, 231-240. [CrossRef] [PubMed]

21. Rullah, K.; Mohd Aluwi, M.F.F.; Yamin, B.M.; Abdul Bahari, M.N.; Wei, L.S.; Ahmad, S.; Abas, F.; Ismail, N.H.; Jantan, I.; Wai, L.K. Inhibition of prostaglandin E2 production by synthetic minor prenylated chalcones and flavonoids: Synthesis, biological activity, crystal structure, and in silico evaluation. Bioorg. Med. Chem. Lett. 2014, 24, 3826-3834. [CrossRef] [PubMed]

22. Shin, S.Y.; Shin, M.C.; Shin, J.-S.; Lee, K.-T.; Lee, Y.S. Synthesis of aurones and their inhibitory effects on nitric oxide and PGE2 productions in LPS-induced RAW 264.7 cells. Bioorg. Med. Chem. Lett. 2011, 21, 4520-4523. [CrossRef] [PubMed]

23. Liu, B.; Zhang, M.; Xie, L.G.; Li, Y.H.; Xu, X. Synthesis, crystal structure and herbicidal activity of aurone derivatives. Chem. J. Chin. Univ. 2011, 32, 2335-2340.

24. Oberoi, S.; Lalita, L. Isolation and characterization of new plant pigment along with three known compounds from Butea monosperma petals. Arch. Appl. Sci. Res. 2010, 2, 68-71.

25. Ahmed, F.A.; Kim, S.Y.; Kurimoto, S.I. Biflavonoids from flowers of Butea monosperma (Lam.) Taub. Heterocycles. 2011, 83, 2079-2089.

26. Zhu, N.; Li, X.-W.; Liu, G.-Y.; Shi, X.-L.; Gui, M.-Y.; Sun, C.-Q.; Jin, Y.-R. Constituents from aerial parts of Bidens ceruna L. and their DPPH radical scavenging activity. Chem. Res. Chin. Univ. 2009, 25, 328-331.

27. Puri, B.; Seshadri, T.R. Survey of anthoxanthins. Part IX. Isolation and constitution of palasitrin. J. Chem. Soc. 1955, 1589-1592. [CrossRef] 
28. Westenburg, H.E.; Lee, K.J.; Lee, S.K.; Fong, H.H.; van Breemen, R.B.; Pezzuto, J.M.; Kinghorn, A.D. Activity-guided isolation of antioxidative constituents of Cotinus coggygria. J. Nat. Prod. 2000, 63, 1696-1698. [CrossRef] [PubMed]

29. Yuan, S.; Liu, M.; Yang, Y.; He, J.-M.; Wang, Y.-N.; Kong, J.-Q. Transcriptome-wide identification of an aurone glycosyltransferase with glycosidase activity from Ornithogalum saundersiae. Genes 2018, 9, 327. [CrossRef] [PubMed]

30. Halbwirth, H.; Wimmer, G.; Wurst, F.; Forkmann, G.; Stich, K. Enzymatic glucosylation of 4-deoxyaurones and 6'-deoxychalcones with enzyme extracts of Coreopsis grandiflora, Nutt. I. Plant Sci. 1997, 122, 125-131. [CrossRef]

31. Yuan, S.; Yin, S.; Liu, M.; He, J.-M.; Kong, J.-Q. OcUGT1-catalyzed glycosylation of testosterone with alternative donor substrates. Process Biochem. 2018, in press. [CrossRef]

32. Yuan, S.; Yang, Y.; Kong, J.-Q. Biosynthesis of 7,8-dihydroxyflavone glycosides via OcUGT1-catalyzed glycosylation and transglycosylation. J. Asian Nat. Prod. Res. 2018. [CrossRef] [PubMed]

33. Yin, S.; Liu, M.; Kong, J.-Q. Functional analyses of OcRhS1 and OcUER1 involved in UDP-L-rhamnose biosynthesis in Ornithogalum caudatum. Plant Physiol. Biochem. 2016, 109, 536-548. [CrossRef] [PubMed]

34. Liu, X.; Kong, J.Q. Steroids hydroxylation catalyzed by the monooxygenase mutant 139-3 from Bacillus megaterium BM3. Acta Pharm. Sin. B 2017, 7, 510-516. [CrossRef] [PubMed]

35. Yin, S.; Kong, J.-Q. Transcriptome-guided gene isolation and functional characterization of UDP-xylose synthase and UDP-d-apiose/UDP-d-xylose synthase families from Ornithogalum caudatum Ait. Plant Cell Rep. 2016, 35, 2403-2421. [CrossRef] [PubMed]

36. Guo, L.; Chen, X.; Li, L.-N.; Tang, W.; Pan, Y.-T.; Kong, J.-Q. Transcriptome-enabled discovery and functional characterization of enzymes related to (2S)-pinocembrin biosynthesis from Ornithogalum caudatum and their application for metabolic engineering. Microb. Cell Fact. 2016, 15, 27. [CrossRef] [PubMed]

(C) 2018 by the authors. Licensee MDPI, Basel, Switzerland. This article is an open access article distributed under the terms and conditions of the Creative Commons Attribution (CC BY) license (http:/ / creativecommons.org/licenses/by/4.0/). 